\title{
Analysis of the stomatognathic system after anterior cruciate ligamentplasty
}

\author{
Bruno Ferreiraa $^{1,2}$, Gabriel Pádua da Silva ${ }^{1,2}$, Edson Donizetti Verri ${ }^{3}$, Marisa Semprinii ${ }^{1}$, Selma Siéssere ${ }^{1}$, \\ Emanuela Martins Nepomuceno ${ }^{4}$, Victor Rodrigues Nepomuceno ${ }^{1}$, Camila Melo de Carvalho ${ }^{1}$, \\ Simone Cecilio Hallak Regalo ${ }^{1}$ \\ ${ }^{1}$ Departamento de Morfologia, Estomatologia e Fisiologia, Faculdade de Odontologia de Ribeirão Preto (FORP-USP), Ribeirão Preto, \\ Brazil \\ ${ }^{2}$ Departamento de Fisioterapia, Centro Universitário UNIFAFIBE, Bebedouro, Brazil \\ ${ }^{3}$ Departamento de Fisioterapia, Centro Universitário Claretiano de Batatais, Batatais, Brazil \\ ${ }^{4}$ Departamento de Fisioterapia, Centro Universitário Luterano de Palmas, Palmas, Brazil \\ Email: brunof22@me.com
}

Received 17 April 2012; revised 4 May 2012; accepted 25 May 2012

\begin{abstract}
Objective: The purpose of this study was to investigate the presence of postural imbalances, which can interfere with the mandible position and affect the actions of the stomatognathic system. Materials and Methods: Forty men, aged between 23 to 29 years, were selected and divided into two groups: Group I comprised 20 healthy individuals with no clinical postural change diagnosis; Group II, 20 individuals who had ACL surgical, unilateral with patellar tendon graft, paired individual to individual (age and weight). All of them were submitted to an electromyography in different clinical conditions. In addition, a condylar biomechanical assessment was performed through videogrametry. Results: In electromyography and videogrametry, a normal standard biomechanical was observed for both groups, however, Group GII-Ligamentplasty presented an inhibition of the masticatory muscles and decreased joint kinesthetic. Conclusion: Based on the results obtained, it was concluded that after the reconstruction of the ACL, individuals presented changes in the stomatognathic system.
\end{abstract}

Keywords: Electromyography; Stomatognathic System; Anterior Cruciate Ligament

\section{INTRODUCTION}

The knee carries heavy loads and is located where the femur meets the tibia, which makes it particularly susceptible to injuries [1,2]. The Anterior Cruciate Ligament injuries (ACL) have been the most common and occur mainly when the knee is in internal rotation and

\footnotetext{
*Analysis of the stomatognathic system.
}

full extension in closed kinematic chain [3,4]. The ACL acts mechanically, limiting the external and internal rotation of the knee. It also acts as a secondary stabilizer to valgus and varus, prevents hyperextension of the knee stress. The ligament has numerous dynamic mechanoreceptors, also acts in proprioception of knee $[5,6]$. The $\mathrm{ACL}$, as well as the posterior cruciate ligament contain pacinian corpuscles, type IV receptors and type I and III mechanoreceptors [7-9].

Following the ACL injury, the periarticular muscles present reflex responses, decreasing the action of the knee extensor muscles and facilitating the action of the flexor muscles [10]. These changes were described to evaluate the onset of the knee muscle activation in different periods after the ligament reconstruction, and obtained distinct chronological orders in muscle activation [6]. Changes in the postural pattern were verified after the ligament reconstruction with a decrease in postural control in individuals with ACL injury after surgery, although they had a subtle improvement in the maintenance of the erect posture [11]. These changes probably occurred due to a decrease in the proprioceptive feedback derived from the ligament injury [9].

The data reported above may influence the actions of the stomatognathic system, where problems in the upper body quadrant may lead to dysfunctions of the anterior positioning of the head, hyperextension over the neck, with jaw retrusion, with the appearance of several kinetic functional disorders, influencing chewing, swallowing, breathing and phonation. These changes can lead to a temporomandibular disorder (TMD), followed by an increase of intolerance to fatigue of the cervical muscle, appearance of trigger points, induction of craniofacial pain, displacement of the hyoid bone, and change in the jaw postural position [12]. The fact that the correlation between two distinct muscular systems are influenced by 
changes generated in one of these systems by anatomic trails, is based on the idea that the muscles act not only individually, but also through connections throughout the body within fascia tracks functionally integrated, composed of connective tissue, with biomechanical function of traction, fixation, compensation, where most of the force vectors are distributed along the anatomic trails [13].

The anatomic trails feature a new perspective for the evaluation and understanding of the biomechanical changes that are taking place, demonstrating that the muscular-skeletal changes of the body generate compensatory muscle imbalance in other muscle systems distinct from the problem [13].

The clinical relevance of this study is to obtain a new scientific approach to improve therapeutic approaches in these patients by dentists, physiotherapists and other health professionals. Evaluate, from a new perspective, the effect of anterior cruciate ligament reconstruction in the function of the stomatognathic system, according to the knowledge of the influence of anatomical trails on the relationship between the masticatory system, muscles and periarticular knee surgery after postural change promoted.

The objective of this study was to evaluate the functionality of the stomatognathic system in individuals after anterior cruciate ligament plasty in order to trace a profile of possible muscular changes of the head, after knee surgery, based on anatomical trails, where changes to the lower segment of the body can promote minor changes in the upper segment.

\section{MATERIALS AND METHODS}

\subsection{Subjective}

Forty men participated to the study, aged between 23 to 29 years ( $24 \pm 2$ years) divided into two groups: Group I (Control) consisting of 20 healthy individuals, without diagnosis of mandibular postural changes clinically evaluated by a dentist. Group II (Patient) 20 individuals with arthroscopic reconstruction of the unilateral anterior cruciate ligament with patellar tendon graft, in six month post-operative, where standard physiotherapeutic rehabilitation was carried out, excluding homogenous adaptations of the musculoskeletal system by paired individual to individual (age and weight). The exclusion criteria were as follows: individuals carrying other pathologies in the lower limb joints or in the contralateral limb; under 18 years old; another graft type; more than six months after surgery and presence of previous postural disorders clinically diagnosed. For the sample calculation was employed the program DIMAM 1.0. Were performed a pilot project and through the program, it was equivalent to the number of subjects for the study.
This research was approved by the Ethics Research Committee of the Centro Universitário Claretiano de Batatais, case N. 14/2010 CEP. The participants were duly clarified and signed the "Term of Free and Informed Consent", according to resolution 196/96 of the National Health Council.

\subsection{Outcome}

For it was possible to investigate the presence of postural imbalance of the mandible can interfered in the activation of the stomatognathic system, was performed methods were used: electromyography and videogrametry.

\subsection{Electromyography}

Electromyographic analysis was performed using a portable MyoSystem-Br1 (São Paulo, Brazil), equipment with 12 channels, eight channels for EMG (for active and passive electrodes), four auxiliary channels, high performance data acquisition system and software for control, storage, processing and data analysis.

The connectors have CC \pm 12 V@ @ \pm 100 mA voltage output, CMRR (common mode rejection ratio) of $112 \mathrm{~dB}$ (a) $60 \mathrm{~dB}, 10^{10} \mathrm{Ohms}$ impedance/6 pf, input bias currents of $\pm 2 \mathrm{nA}$ for active electrodes, protection against overvoltage and band pass filters to eliminate noise with frequencies from $5 \mathrm{~Hz}$ to $5 \mathrm{KHz}$. The simple differential surface active electrodes were used with two contacts of $10.0 \times 1.0 \mathrm{~mm}$ to $10.0 \mathrm{~mm}$ distance between them, and were fixed in resin encapsulation $(40 \times 20 \times 5 \mathrm{~mm})$.

The electrodes were placed on the following muscles: right masseter (RM), left masseter (LM), right temporalis (RT) and left temporalis (LT), right sternocleidomastoid (RSCM) and left sternocleidomastoid (LSCM). A voluntary contraction maneuver was performed to locate the best point for the positioning of the electrodes [14]. The masticatory muscular activity was electromyographically analyzed during rest and the activities involving the effective participation of these muscles in the following clinical positions: Rest (4 sec); Maximum voluntary contraction (4 sec) (normalization factor); Protrusion, left and right lateralities with dental contact $(10 \mathrm{sec})$. The electromyographic activity was normalized by maximum voluntary contraction.

The electromyographic signals were captured with the subjects comfortably seated in a chair, their arms next to their body and hands on their thighs. The head was erect, parallel to the ground.

Prior to the completion of each experiment, the participants received the necessary instructions and explanations and were asked to remain as calmer as possible, breathing normally.

The electromyographic signals were processed using a MyoSystem-Br1 version 3.56. After digitalization, the 
signals were analogically amplified with a gain of 1000 , filtered by a pass-band of $0.02-2 \mathrm{kHz}$ and sampled by a 12-bit A/D converter with a $2 \mathrm{kHz}$ sampling rate.

\subsection{Videogrametry}

The videogrametry was performed using a Kodak P880 digital, with camera positioned on a tripod $90 \mathrm{~cm}$ from the ground, $3 \mathrm{~m}$ from the individual. For the procedure, points were marked using the following structures: superior mentalis and inferior-labial process, zygomotic bones and ear tragus [15]. The specific anatomical landmarks were marked with a surgical marker pen for the application of an adhesive paper on the points.

After each collection, the videos were transferred to the computer in QuickTime (MOV), converted into Windows extension (WMV) and analyzed by the Quintic Biomechanics v17 version 9.03; it digitized 4 (four) angles: mandible in right (MDR) and left hemifaces (MDL), and maxilla in right (MXR) and left hemifaces (MXL) of each clinical condition.

\subsection{Statistic Analyzes}

Standardized electromyographic and viodeogrametry data were tabulated and subjected to data analysis using SPSS 17.0 version for Windows (SPSS Inc.; Chicago, IL, USA). Descriptive analysis was held (means, standard deviations). The values obtained were compared by t-test analysis $(\mathrm{p} \leq 0.05)$.

\section{RESULTS}

\subsection{Electromyographic Data}

At rest, there was a decline of muscular activity in GII observed in most muscles. The data obtained were not statistically significant at electromyographic signals were processed $\mathrm{p} \leq 0.05$ (Table 1).

In protrusion, it was verified that individuals in GII did not present the muscular standard expected. The masseter muscles should be more active than the temporal ones, a fact observed in GI. There was also activation of the sternocleidomastoid muscles for the groups evaluated. All the data obtained were not statistically significant at $\mathrm{p} \leq 0.05$ (Table 2).

In the right laterality, a greater activation of the right temporal muscles in the groups was observed, which is considered standard. For the masseter muscles, in both groups evaluated, the left muscles were more active than the right ones, which were expected. The data were statistically significant for the right temporal muscles to at $\mathrm{p}$ $\leq 0.05$ (Table 3).

In the left laterality, a greater activation of the left temporal muscles in the groups was also observed. For the masseter muscles, in both groups evaluated, the right
Table 1. Normalized electromyographic means and standard error of the Right Temporalis (RT) and Left (LT) muscles, Right (RM) and Left (LM) Masseter and Right (RSCM) and Left (LSCM) Sternocleidomastoid in GI and GII at Rest (TTest at $\mathrm{p} \leq 0.05)$.

\begin{tabular}{|c|c|c|c|c|}
\hline Muscles & Groups & $\mathrm{p}$ & Mean & Stand Error \\
\hline \multirow{2}{*}{ Right temporalis } & GI-Control & \multirow{2}{*}{$0.80^{\mathrm{ns}}$} & 0.04 & \pm 0.00 \\
\hline & GII-Patient & & 0.04 & \pm 0.00 \\
\hline \multirow{2}{*}{ Left temporalis } & GI-Control & \multirow{2}{*}{$0.29^{\text {ns }}$} & 0.07 & \pm 0.01 \\
\hline & GII-Patient & & 0.04 & \pm 0.00 \\
\hline \multirow{2}{*}{ Right Masseter } & GI-Control & \multirow{2}{*}{$0.13^{\text {ns }}$} & 0.07 & \pm 0.01 \\
\hline & GII-Patient & & 0.04 & \pm 0.00 \\
\hline \multirow{2}{*}{ Left Masseter } & GI-Control & \multirow{2}{*}{$0.78^{\text {ns }}$} & 0.08 & \pm 0.01 \\
\hline & GII-Patient & & 0.07 & \pm 0.02 \\
\hline \multirow{2}{*}{$\mathrm{RSCM}$} & GI-Control & \multirow{2}{*}{$0.34^{\mathrm{ns}}$} & 0.52 & \pm 0.04 \\
\hline & GII-Patient & & 0.44 & \pm 0.05 \\
\hline \multirow{2}{*}{ LSCM } & GI-Control & \multirow{2}{*}{$0.72^{\text {ns }}$} & 0.46 & \pm 0.03 \\
\hline & GII-Patient & & 0.48 & \pm 0.04 \\
\hline
\end{tabular}

${ }^{\text {ns }}$ Non-standard.

Table 2. Normalized electromyographic means and standard error of the Right Temporalis (RT) and Left (LT) muscles, Right (RM) and Left (LM) Masseter, Right (RSCM) and Left (LSCM) Sternocleidomastoid in GI and GII in Potrusion (TTest at $\mathrm{p} \leq 0.05$ ).

\begin{tabular}{ccccc}
\hline Muscles & Groups & $\mathrm{p}$ & Mean & Standard Error \\
\hline \multirow{2}{*}{ Right temporalis } & GI-Control & $0.12^{\text {ns }}$ & 0.05 & \pm 0.00 \\
& GII-Patient & & 0.10 & \pm 0.03 \\
Left temporalis & GI-Control & $0.45^{\text {ns }}$ & 0.06 & \pm 0.00 \\
& GII-Patient & & 0.09 & \pm 0.04 \\
& GI-Control & \multirow{2}{*}{$0.26^{\text {ns }}$} & 0.27 & \pm 0.03 \\
Right Masseter & GII-Patient & & 0.35 & \pm 0.04 \\
& GI-Control & \multirow{2}{*}{$0.39^{\text {ns }}$} & 0.26 & \pm 0.03 \\
Left Masseter & GII-Patient & & 0.42 & \pm 0.06 \\
& GI-Control & \multirow{2}{*}{$0.51^{\mathrm{ns}}$} & 1.25 & \pm 0.17 \\
& GII-Patient & & 1.11 & \pm 0.13 \\
LSCM & GI-Control & \multirow{2}{*}{$0.51^{\mathrm{ns}}$} & 1.39 & \pm 0.31 \\
& GII-Patient & & 1.91 & \pm 0.71 \\
\hline
\end{tabular}

${ }^{\text {ns }}$ Non-standard.

muscles were more active than the left ones, which was expected. The data were not statistically significant at $p$ $\leq 0.05$ (Table 4).

\subsection{Videogrametry Data}

At rest, the videogrametric analysis found that individuals in GII presented mandible deviation to the right side; however, the deviation was smaller than in GI, which 
Table 3. Normalized electromyographic means and standard error of the Right Temporalis (RT) and Left (LT) muscles, Right (RM) and Left (LM) Masseter, Right (RSCM) and Left (LSCM) Sternocleidomastoid in GI and GII in the Right Laterality (T-Test at $\mathrm{p} \leq 0.05$ ).

\begin{tabular}{|c|c|c|c|c|}
\hline Muscles & Groups & $\mathrm{p}$ & Mean & Standard Error \\
\hline \multirow{2}{*}{ Right temporalis } & GI-Control & \multirow{2}{*}{$0.05^{*}$} & 0.10 & \pm 0.02 \\
\hline & GII-Patient & & 0.22 & \pm 0.05 \\
\hline \multirow{2}{*}{ Left temporalis } & GI-Control & \multirow{2}{*}{$0.21^{\mathrm{ns}}$} & 0.06 & \pm 0.01 \\
\hline & GII-Patient & & 0.11 & \pm 0.04 \\
\hline \multirow{2}{*}{ Right Masseter } & GI-Control & \multirow{2}{*}{$0.90^{\text {ns }}$} & 0.17 & \pm 0.06 \\
\hline & GII-Patient & & 0.17 & \pm 0.05 \\
\hline \multirow{2}{*}{ Left Masseter } & GI-Control & \multirow{2}{*}{$0.61^{\mathrm{ns}}$} & 0.18 & \pm 0.05 \\
\hline & GII-Patient & & 0.18 & \pm 0.04 \\
\hline \multirow{2}{*}{ RSCM } & GI-Control & \multirow{2}{*}{$0.62^{\mathrm{ns}}$} & 1.29 & \pm 0.02 \\
\hline & GII-Patient & & 0.21 & \pm 0.20 \\
\hline \multirow{2}{*}{ LSCM } & GI-Control & \multirow{2}{*}{$0.49^{\mathrm{ns}}$} & 1.45 & \pm 0.36 \\
\hline & GII-Patient & & 2.00 & \pm 0.70 \\
\hline
\end{tabular}

"Significance at $\mathrm{p}<0.05 ;{ }^{\mathrm{ns}}$ Non-standard.

Table 4. Normalized electromyographic means and Standard Error of the Right Temporalis (RT) and Left (LT) muscles, Right (RM) and Left (LM) Masseter, Right (RSCM) and Left (LSCM) Sternocleidomastoid in GI and GII in Left Laterality (T-Test at $\mathrm{p} \leq 0.05$ ).

\begin{tabular}{ccccc}
\hline Muscles & Groups & $\mathrm{p}$ & Mean & Standard Error \\
\hline \multirow{2}{*}{ Right temporalis } & GI-Control & $0.28^{\text {ns }}$ & 0.04 & \pm 0.00 \\
& GII-Patient & & 0.09 & \pm 0.03 \\
& GI-Control & & 0.13 & \pm 0.02 \\
Left temporalis & GII-Patient & $0.25^{\text {ns }}$ & 0.21 & \pm 0.05 \\
& GI-Control & & 0.16 & \pm 0.14 \\
Right Masseter & GII-Patient & $0.63^{\text {ns }}$ & 0.19 & \pm 0.28 \\
& GI-Control & & 0.14 & \pm 0.04 \\
Left Masseter & GII-Patient & $0.63^{\text {ns }}$ & 0.17 & \pm 0.05 \\
& GI-Control & & 0.94 & \pm 0.04 \\
RSCM & GII-Patient & $0.17^{\text {ns }}$ & 0.72 & \pm 0.04 \\
& GI-Control & & 1.55 & \pm 0.07 \\
& GII-Patient & $0.20^{\text {ns }}$ & 2.74 & \pm 0.87 \\
\hline
\end{tabular}

${ }^{\text {ns Non-standard. }}$

exhibited greater mandible displacement to the left. The data were statistically significant at $\mathrm{p} \leq 0.05$ (Table 5).

In protrusion, it was observed that individuals in GII presented mandible deviation to the right side. The values obtained were statistically significant at $p \leq 0.05$, except the right mandible deviation (Table 6).

In the right laterality, the GII presented greater deviation of mandible for both sides, predominantly to the right. The values obtained were statistically significant only for the right maxilla at $p \leq 0.05$ (Table 7). In left laterality, the greatest values were observed in the GI, except for the right mandible deviation. The values obtained were statistically significant at $p \leq 0.05$, except for the right mandible and left maxillary deviation (Table 8).

\section{DISCUSSION}

The pain in the neck and shoulder tends to generate a

Table 5. Mean angles (Degrees) and standard error of Right (RMD) and Left (LMD) mandible angle axes, Right (RMX) and Left (LMX) Maxilla in GI and GII at Rest (T-Test at $\mathrm{p} \leq$ $0.05)$.

\begin{tabular}{|c|c|c|c|c|c|}
\hline $\begin{array}{l}\text { Angle } \\
\text { Axes }\end{array}$ & Hemiface & Groups & $\mathrm{p}$ & Mean & $\begin{array}{c}\text { Standard } \\
\text { Error }\end{array}$ \\
\hline \multirow[t]{2}{*}{ Mandible } & \multirow[t]{2}{*}{ Right } & GI-Control & \multirow[t]{2}{*}{$0.01^{* *}$} & 124.85 & \pm 2.85 \\
\hline & & GII-Patient & & 136.83 & \pm 1.65 \\
\hline \multirow{2}{*}{ Mandible } & \multirow{2}{*}{ Left } & & \multirow{2}{*}{$0.04^{*}$} & 131.41 & \pm 3.97 \\
\hline & & GII-Patient & & 145.64 & \pm 2.43 \\
\hline \multirow{2}{*}{ Maxilla } & \multirow{2}{*}{ Right } & & \multirow{2}{*}{$0.00^{* *}$} & 111.44 & \pm 4.90 \\
\hline & & GII-Patient & & 91.28 & \pm 3.25 \\
\hline \multirow{2}{*}{ Maxilla } & \multirow{2}{*}{ Left } & GI-Control & \multirow{2}{*}{$0.04^{*}$} & 100.73 & \pm 4.75 \\
\hline & & GII-Patient & & 89.37 & \pm 2.53 \\
\hline
\end{tabular}

${ }^{* *}$ Significance at $\mathrm{p}<0.01 ;{ }^{*}$ Significance at $\mathrm{p}<0.05 ;{ }^{\mathrm{ns}}$ Non-standard.

Table 6. Mean angles (Degrees) and standard error of Right (RMD) and Left (LMD) mandible angle axes, Right (RMX) and Left (LMX) Maxilla in GI and GII in Protrusion (T-Test at $\mathrm{p} \leq 0.05)$

\begin{tabular}{cccccc}
\hline $\begin{array}{c}\text { Angle } \\
\text { Axes }\end{array}$ & Hemiface & Groups & $\mathrm{p}$ & Mean & $\begin{array}{c}\text { Standard } \\
\text { Error }\end{array}$ \\
\hline \multirow{2}{*}{ Mandible } & \multirow{2}{*}{ Right } & GI-Control & $0.16^{\mathrm{ns}}$ & 128.52 & \pm 2.78 \\
& & GII-Patient & & 134.00 & \pm 2.68 \\
Mandible & \multirow{2}{*}{ Left } & GI-Control & & 100.51 & \pm 5.41 \\
& & GII-Patient & $0.01^{* *}$ & 87.37 & \pm 2.92 \\
Maxilla & \multirow{2}{*}{ Right } & GI-Control & & 103.55 & \pm 5.11 \\
& & GII-Patient & $0.01^{* *}$ & 87.01 & \pm 4.02 \\
& & GI-Control & & 131.70 & \pm 3.84 \\
Maxilla & Left & GII-Patient & $0.03^{*}$ & 142.77 & \pm 1.71 \\
\hline
\end{tabular}

${ }^{* *}$ Significance at $\mathrm{p}<0.01 ;{ }^{*}$ Significance at $\mathrm{p}<0.05 ;{ }^{\text {ns }}$ Non-standard. 
Table 7. Mean angles (degrees) and standard error of Right (RMD) and Left (LMD) mandible angle axes, Right (RMX) and Left (LMX) Maxilla in GI and GII in Right Laterality (T-Test at $\mathrm{p} \leq 0.05)$.

\begin{tabular}{cccccc}
\hline $\begin{array}{c}\text { Angle } \\
\text { Axes }\end{array}$ & Hemiface & Groups & $\mathrm{p}$ & Mean & $\begin{array}{c}\text { Standard } \\
\text { Error }\end{array}$ \\
\hline \multirow{2}{*}{ Mandible } & \multirow{2}{*}{ Right } & GI-Control & $0.08^{\mathrm{ns}}$ & 138.27 & \pm 4.08 \\
& & GII-Patient & & 147.03 & \pm 2.70 \\
Mandible & Left & GI-Control & & 120.23 & \pm 4.08 \\
& & GII-Patient & $0.07^{\mathrm{ns}}$ & 129.19 & \pm 2.55 \\
Maxilla & \multirow{2}{*}{ Right } & GI-Control & & 104.89 & \pm 6.14 \\
& & GII-Patient & $0.03^{*}$ & 88.69 & \pm 4.39 \\
& & GI-Control & & 101.63 & \pm 4.44 \\
Maxilla & Left & GII-Patient & $0.21^{\mathrm{ns}}$ & 95.11 & \pm 2.62 \\
\hline
\end{tabular}

"Significante para $\mathrm{p}<0.05 ;{ }^{\mathrm{ns}}$ Non-standard.

Table 8. Mean angles (degrees) and standard error of Right (RMD) and Left (LMD) mandible angular axes, Right (RMX) and Left (LMX) Maxilla in GI and GII in Left Laterality (T-Test at $\mathrm{p} \leq 0.05)$.

\begin{tabular}{cccccc}
\hline $\begin{array}{c}\text { Angle } \\
\text { Axes }\end{array}$ & Hemiface & Groups & $\mathrm{p}$ & Mean & $\begin{array}{c}\text { Standard } \\
\text { Error }\end{array}$ \\
\hline \multirow{2}{*}{ Mandible } & Right & GI-Control & $0.36^{\mathrm{ns}}$ & 116.19 & \pm 3.19 \\
& & GII-Patient & & 119.74 & \pm 2.17 \\
Mandible & Left & GI-Control & & 142.86 & \pm 5.31 \\
& & GII-Patient & & 154.99 & \pm 2.24 \\
Maxilla & \multirow{2}{*}{ Right } & GI-Control & & 107.06 & \pm 4.83 \\
& & GII-Patient & $0.05^{*}$ & 94.85 & \pm 3.98 \\
& & GI-Control & & 100.88 & \pm 7.10 \\
Maxilla & Left & GII-Patient & $0.06^{\mathrm{ns}}$ & 86.34 & \pm 2.44 \\
\hline
\end{tabular}

* Significance at $\mathrm{p}<0.05 ;{ }^{\text {ns }}$ Non-standard.

certain posture which will trigger other postural and biochemical compensations in the body. In addition, it can also increase the perception of pain, anxiety, hyper-activation of the accessory muscles and smooth muscle contraction that comprise the blood vessel walls, which act together to decrease the release of oxygen by hemoglobin molecule carriers causing fatigue to the brain and muscles. These statements show the changes between independent systems that can jointly generate changes in the body to seek global homeostasis [13].

EMG is a safe and effective technique for evaluating and recording the muscular activity in healthy or dysfunctional individuals allowing to observe how the muscle is activated and to determine its coordination [16-19]. The electromyographic analysis in healthy individuals and individuals after knee ligament reconstruction was used to measure the bilateral EMG activity patterns of the temporal, masseter and sternocleidomastoid muscles, at rest and in different clinical postural conditions of the mandible in order to investigate the functional changes of the stomatognathic system, following a knee ligament surgery.

The videogrametry analysis was important as it generated indirect indicators measures obtained through images that size the motion kinematic parameters of the eletromiographic clinical positions proposed in this study. It aimed to analyze the kinematics of mandible postural positions by checking the possibility of interference from the ACL surgery associated with the upper quadrant (Stomatognathic system).

At rest, the EMG activity for the muscles on both sides, in two groups, indicated that in order to maintain this postural condition, the activation of all muscle fibers is necessary, with the activity of masseter and sternocleidomastoid muscles being well marked, especially in the control group individuals. This was an interesting result considering that the electromyographic literature shows that the muscles at rest do not display myoelectric activity. Consequently, there are no traction units with contraction, although some authors have found minimal electrical activity in muscles associated with the process of mastication [20-23].

A greater activation of the temporal muscles was not observed in any of the groups, contrary to the results reported by Cecílio et al. [24], who verified greater temporal muscle activation at rest that occurred in all age groups for healthy individuals, justifying it by the function of the temporal muscles in the mandible positioning.

The low tonic activity of the mastication muscles at rest is controlled by sensory receptors and the central nervous system. Changes in the balance of these systems can cause changes in the masticatory system [25]. For GII, functional balance did not occur between the right and left sides in muscle activation, differently from GI, where the right and left sides had similar values, demonstrating that the musculatures were in balance during this activity.

In videogrametric, the GII presented an increase in mandibular angle to the right side, evidencing a change in the posture of the mandible at rest, similar to what occurred with the electromyography. The GI exhibited an angular balance in the mandible and maxilla showing deviation for both sides.

These changes which were verified at rest, during the electromyography and kinemetrics, may be related to the changing in length of the mandible muscles due to postural changes. At rest, the mandible positioning is influenced by the muscles that are inserted in the mandible. Such differences can cause changes in compensation of 
other muscles such as those in the shoulder girdle and cervical spine, and therefore, change the whole musculoskeletal balance.

Howells et al. [11] stated that, after an anterior cruciate ligamentplasty, it is possible to find moderate changes in posture due to the knee proprioceptive influence. Postural alignment and synchronicity are interconnected by visual stimulation, general bodily proprioceptive sensitivity and the vestibular apparatus. All these systems are interdependent from the harmony of other adjacent systems, among them, the stomatognathic system. This way, postural imbalances can cause alterations in the individual's postural awareness [22].

Cecilio et al. [23] reported that psychological stress and other sources of tension have an impact on the muscle tension and may cause inappropriate activity of the masticatory muscles by directly influencing the appearance of changes in stomatognathic system components. The muscle tension that occurs during situations considered emotionally painful is an important etiological factor in many dysfunctions [26]. However, in this study, the individuals were evaluated after six months following the surgical procedure, and the imbalance of the biomechanical muscle activity was probably not related to the post-operative stress.

In protrusion, during electromyography, all groups have presented a typical pattern of contraction to maintain the position, consisting of greater activation of the masseter muscles, when compared with the temporal muscles, corroborating the results obtained by Cecílio et al. [23]. In the kinemetric analysis, it was observed that the groups showed mandible deviation to the right side. This may have been determined by the central nervous system preferred predominance to this particular side, as our population under study was right-handed.

During the lateral movement of the jaw, it is known that there is a neuroanatomical pattern of muscular activation in which an increased EMG activity is recorded in the temporal muscle, in the same side of the mandible, which extends to functional side. As for the masseter muscle, the greatest contralateral activity is expected $[17,23,27]$. This activation pattern has been observed in two groups analyzed in the right and left lateralities.

In the right laterality, considering the kinematic evaluation, the groups showed a greater mandible deviation to the right side, evidencing a pattern of normality to this movement. The GII presented smaller amplitude of right laterality than the GI. In the left, the two groups also showed greater mandible deviation to the left side, while in GI a greater range of motion of this articulation occurred, evidencing compensation for the loss of stimulation of the mandible positioning in GII.

Individuals with ligament injury showed a loss of knee function with a decrease of proprioception and sensitive mechanisms. When there is loss of ligaments, the individuals can exhibit changes in the joint position, an increase in time for passive motion detection, joint instabilities and reflex motor response of the ischiotibial muscles [28,29].

These changes may justify the kinematic changes found in this study, where the work of anatomical trains by the deep anterior and lateral lines, which are interlinked in the muscles of the knee and stomatognathic system, generated a kinematic standard of perception loss of the motion evidenced by the decreased kinematics of individuals with ligamentplasty by the decrease of angulations obtained, revealing some difficulty for the individuals to perceive the movements they performed.

Results showed that the injuries and the ACL reconstruction surgery promoted a modification of the chewing pattern. Health professionals should render more attention to the individuals as a whole, because the influence of anatomical trains is a reality.

\section{ACKNOWLEDGEMENTS}

The authors wish to thank Fundação de Amparo a Pesquisa do Estado de São Paulo-FAPESP (2010/07513-5) for financially supporting this research.

\section{REFERENCES}

[1] Foster, T.E., Wolfe, B.L., Ryan, S., Silvestri, L. and Kaye, E.K. (2010) Does the graft source really matter in the outcome of patients undergoing anterior cruciate ligament reconstruction? An evaluation of autograft versus allograft reconstruction results: A systematic review. Ameican Journal Sports Medicine, 38, 189-199. doi:10.1177/0363546509356530

[2] Nordin, M. and Frankel, V.H. (2003) Basic biomechanics of the musculoskeletal system. 3rd Edition, Lippincott Williams \& Wilkins, New York

[3] Hirokawa, S., Solomonow, M., Lu, Y., Lou, Z. and Ambrosia, R. (1992) Anterior-posterior and rotational displacement of the tibia elicited by quadriceps contraction. American Journal Sports Medicine, 20, 299-306. doi: $10.1177 / 036354659202000311$

[4] Keene, G.C., Bickerstaff, D., Rae, P.J. and Paterson, R.S. (1993). The natural history of meniscal tears in anterior cruciate ligament insufficiency. American Journal Sports Medicine, 21, 672-679. doi: $10.1177 / 036354659302100506$

[5] Chu, D., LeBlanc, R., Ambrosia, P.D., Ambrosia, R.D., Baratta, R.V. and Solomonow M. (2003) Neuromuscular disorder in response to anterior cruciate ligament creep. Clinical Biomechanics, 18, 222-230. doi:10.1016/S0268-0033(03)00002-0

[6] Fatarelli, I.F.C., Almeida, G.L. and Nascimento, B.G. (2004) ACL injury and reconstruction: A review of the biomechanics and motor control. The Journal Brazilian Physiotherapy, 8, 197-206. 
[7] Cole, K.J., Brand, R.A. and Daley, B.J. (1995) The sensitivity of joint afferents to knee translation. The Iowa Orthopaedic Journal, 15, 168-173.

[8] Foster, T.E. and Zarins, B. (1994) Posterior cruciate ligament injuries. In: Siliski, J.M., Ed., Traumatic Disorders of the Knee, 1st Edition, Springer, Boston. doi:10.1007/978-1-4612-4310-6 16

[9] Reider, B., Arcand, M.A., Diehl, L.H., Mroczek, K., Abluencia, A., Stroud, C.C., Palm, M., Gilbertson, J. and Staszak, P. (2003) Proprioception of the knee before and after anterior cruciate ligament reconstruction. The Journal of Arthroscopic and Related Surgery, 19, 2-12. doi:10.1053/jars.2003.50006

[10] Berchuck, M., Andriacchi, T.P., Bach, B.R. and Reider, B. (1990) Gait adaptations by patients who have a deficient anterior cruciate ligament. The Journal of Bone and Joint Surgery, 72-A, 871-877.

[11] Howells, B.E., Ardern, C.L. and Webster, K.E. (2011) Is postural control restored following anterior cruciate ligament reconstruction? A systematic review. Knee Surgery Sports Traumatology Arthroscopy, 19, 1168-1177. doi:10.1007/s00167-011-1444-X

[12] Strini, P.J.S.A., Machado, N.A.G., Gorreri, M.C., Ferreira, A.F., Sousa, G.C. and Fernandes, N.A.J. (2009) Postural evaluation of patients with temporomandibular disorders under use of occlusal splints. Journal of Applied Oral Science, 17, 539-543. doi:10.1590/S1678-77572009000500033

[13] Myers, T.W. (2009) Anatomy trains: Myofascial meridians for manual and movement therapists. 2nd Edition, Livingstone, Churchill.

[14] Cram, J.R., Kasman, G.S. and Holtz, J. (1998) Introduction to surface electromyography. Aspen Publication, Gaithersburg.

[15] Miranda, J.S., Marques, J.S., Mauro, M.C.F.L. and Mercadante, L.A. (2009) Method for describing the movement of the mandibular condyles by videogrametry. 18th Congresso Brasileiro de Fisioterapia, Rio de Janeiro.

[16] Ferrario, V.F., Serrao, G., Dellavia, C., Caruso, E. and Sforza, C. (2002) Relationship between the number of occlusal contacts and masticatory muscle activity in health young adults. Clinics, 20, 91-98.

[17] Pancherz, H. (1980) Temporal and masseter muscle activity in children and adults with normal occlusion. Acta Odontologica Scandinavica, 38, 343-348. doi:10.3109/00016358009033603

[18] Regalo, S.C., Santos, C.M., Vitti, M., Regalo, C.A., Vasconcelos, P.B., Mestriner, J.R.W., Semprini, M., Dias, F.J., Hallak, J.E. and Siéssere, S. (2008) Evaluation of molar and incisor bite force in indigenous compared with white population in Brazil. Archives Oral Biology, 53, 282-286. doi:10.1016/j.archoralbio.2007.10.003

[19] Sbriccoli, P., Solomonow, M., Zhou, B., Lu, Y. and Sel- lards, R. (2005) Neuromuscular response to cyclic loading of the anterior cruciate ligament. American Journal of Sports Medicine, 33, 543-551. doi: $10.1177 / 0363546504268408$

[20] Chong, S.S., Ouyang, G. and Tian, W.G. (1991) Power spectral analysis of electromyografic signal of mastigatory muscles at rest position and habitual clench. Journal of Prosthetic Dentistry, 65, 553-556. doi:10.1016/0022-3913(91)90299-C

[21] Hermens, H.J., Freriks, B., Disselhorst-Klug, C. and Rau, G. (2000) Development of recommendations for SEMG sensors and sensor placement procedures. Journal Electromyography and Kinesiology, 10, 361-374. doi:10.1016/S1050-6411(00)00027-4

[22] Ngawhirunpat, T., Hatanaka, T., Katayama, K., Yoshikawa, H., Kawakami, J. and Adachi, I. (2002) Changes in electrophysiological properties of rat skin with age. Biological and Pharmaceutical Bulletin, 25, 1192-1196. doi:10.1248/bpb.25.1192

[23] Regalo, S.C., Vitti, M., Semprini, M., Rosa, L.B., Martinez, F.H., Santos, C.M. and Hallak, J.E. (2006) Electromyographic analysis of the masseter and temporal muscles in oralized deaf individuals. Electromyography and Clinical Neurophysiology, 46, 217-222.

[24] Cecilio, F.A., Regalo, S.C.H., Palinkas, M., Issa, J.P.M., Siéssere, S. and Hallak, J.E.C. (2010) Aging and surface EMG activity patterns of masticatory muscles. Journal Oral Rehabilitation, 37, 248-255. doi:10.1111/j.1365-2842.2010.02051.x

[25] Sabashi, K., Saitoh, I., Hayasaki, H., Iwase, Y., Kondo, S., Inada, E., Takemoto, Y., Yamada, C. and Yamasaki, Y. (2009) A cross-sectional study of developing resting masseter activity in different angle classifications in adolescence. Clinics, 27, 39-45.

[26] Uha, C.I., Kovac, Z., Valentic-Peruzóvic, M., Jurétic, M., Moro, L.J. and Grzíc, R. (2003). The influence of war stress on the prevalence of signs and symptoms of temporomandibular disorders. Journal Oral Rehabilitation, 30, 211-217. doi:10.1046/j.1365-2842.2003.01030.x

[27] Blanksma, N.G. and Van Eijden, T.M. (1995) Electromyographic heterogeneity in the human temporalis and masseter muscles during static biting, open/close excursions, and chewing. Journal of Dental Research, 74, 1318-1327. doi:10.1177/00220345950740061201

[28] Cuccia, A. and Caradonna, C. (2009) The relationship between the stomatognathic system and body posture. Clinics, 64, 61-66. doi:10.1590/S1807-59322009000100011

[29] Valeriani, M., Restuccia, D., Di Lazzaro, V., Franceschi, F., Fabbriciani, C. and Tonali, P. (1999) Clinical and neurophysiological abnormalities before and after reconstruction of the anterior cruciate ligament of the knee. Acta Neurologica Scandinavic, 99, 303-307. doi:10.1111/j.1600-0404.1999.tb00680.x 